\author{
E. Ripetskyy ${ }^{1}$, R. Ripetskyy ${ }^{1}$, M. Pidgurskyi ${ }^{2}$, I. Pidgurskyi ${ }^{2}$, O. Korobkov ${ }^{1}$
}

\title{
Adaptation of Energy Methods to Automated Calculation of Mobile Machines Frame Constructions
}

\author{
${ }^{1}$ Ivano-Frankivsk National Technical University of Oil and Gas, ${ }^{1}$ Ivano-Frankivsk, Ukraine, erip@i.ua \\ ${ }^{2}$ Ternopil Ivan Puluj National Technical University, Ternopil, Ukraine, pidhurskyy@gmail.com
}

\begin{abstract}
The paper shows that the adaptation of energy methods to automated calculation of mobile machines frame constructions consists of developing a single algorithm applicable to different construction schemes. The calculation outset still remains the idea of getting a function of potential energy of deformation as a function with unknown inner power factors. Search for local function minimum of potential power of deformation has been based on the function's discrete grid-surface. We managed to reach tactical flexibility of coordinate descent method in an attempt to continue approaching local minimum in cases of a dead end situation by changing the discrete course. The paper suggests extending the implemented algorithm from 3-D surface dealing only with two power factors, to $\mathrm{n}-\mathrm{D}$ one with many unknown values.

Key words: energy methods, frame construction, potential energy of deformation, inner power factors, gridsurfaces, coordinate descent method.
\end{abstract}

Received 17 March 2021; Accepted 14 May 2021.

\section{Introduction}

Current trends in the engineering design of mobile machinery are closely linked to the development of computer technology and the emergence of new universal applications. Computational models which can significantly accelerate the processes of the most complex calculations are widely used. Such models are especially successfully applied in calculations to determine the stress-strain state (SSS) of complex structural structures.

One of the most loaded elements of mobile machinery is the frame, which is a spatial load-bearing metal structure and consists of numerous closed contours. In each such contour at an arbitrary external load, there are six internal force factors, the determination of which from the static equations becomes impossible.

A sufficiently effective method of calculating such load-bearing systems is the energy method of minimum potential deformation energy, which allows determining all internal force factors [1].
However, the method involves a large number of analytical transformations associated with the disclosure of static uncertainty of the frame. Individual algorithmization of the method for each frame structure does not make it fully applicable in automated calculations of frame structures.

The use of modern automated methods for calculating the frame structures of mobile machines will significantly accelerate the process of their design as well as increase the reliability of the machine through a reasonable choice of the optimal version of the bearing system.

The developed methods can be designed in the form of application packages with their subsequent implementation in CAD for the calculation and analysis of the load of frame structures.

\section{Formulation of the problem}

In the current practice of designing mobile machines frames, there is a significant share of manual operations in calculating their strength, associated with the 
processing of volumetric math functions of loads with the disclosure of static uncertainty of load-bearing structures. In the energy method, when statically indeterminate structural structures are considered, the main emphasis is on obtaining the function of the potential energy of the basic calculation schemes under the action of both external load and many unknown internal force factors. Operations for calculating partial derivatives of the total potential energy allow forming a system of canonical equations, which corresponds to the number of unknowns [1-5].

Integrand functions of potential deformation energies functions are functions of the second degree, the solution to which using the classical method leads to volumetric math functions. In order to simplify the calculations to determine the stress-strain state of the frame structure under the action of external loads arising during its operation, a modified method of minimum potential deformation energy (MMPDE) is proposed. It is proved that the use of MMPDE is effective for a plane closed frame structure made of thin-walled profiles, loaded with forces perpendicular to the plane of the frame. These circumstances allow neglecting the energies from compression and shear, as they do not significantly affect the accuracy of the results [1-5].

However, the modified method does not completely eliminate the operations of transforming volumetric math functions, but only reduces their number. In addition, the algorithmization of the calculation for MMPDE depends on the design of the frame, which is an obstacle to the implementation of end-to-end automation of calculations in the design of frame structures.

At the same time, among the alternative methods of automated frames calculation is the finite element method (FEM). The advantages of FEM in comparison with traditional numerical methods are the simplicity of algorithmization, the possibility of full automation in compiling equations, and obtaining results for fairly complex combined systems [6]. As the result of this calculation, the diagrams of stress and strain distribution in structural elements are received. However, this technique does not allow determining the internal force factors. Therefore, according to the obtained diagrams, it is impossible to determine the role of each force factor in the total picture of the SSS of the structure [7].

The actual use of energy methods for automated calculations of frame structures of mobile machinery will decrease the share of manual operations, reduce the design time of frame structures, as well as move to the dialogue tools of CAD in finding reasonable parameters of load-bearing systems of mobile machines.

\section{Analysis of recent research and publications}

Theoretical principles of application of energy methods to the calculation of frame structures are carried out for a number of mobile machines, such as sprayers [1], beet harvesters [2], trailed fertilizer spreaders PRT10 [3], autonomous grab loaders PEA-1,0 and PEA-1A [4] and others. The problem is considered solved if the values of internal force factors are found. Assuming that the solution of the problem corresponds to the condition of the minimum of the obtained functional of the potential deformation energy $U$

$$
\begin{array}{r}
\mathrm{U}\left(\mathrm{M}_{1}, \mathrm{M}_{2}, \ldots \mathrm{M}_{\mathrm{i}}, \mathrm{Q}_{1}, \mathrm{Q}_{2}, \ldots \mathrm{Q}_{\mathrm{i}}, \mathrm{N}_{1},\right. \\
\left.\mathrm{N}_{2}, \ldots \mathrm{N}_{\mathrm{i}}, \mathrm{K}_{1}, \mathrm{~K}_{2}, \ldots \mathrm{K}_{\mathrm{i}}\right) \rightarrow \min
\end{array}
$$

The authors then follow the same scheme, namely, compile canonical equations to find the unknown internal force factors of bending moments $M_{i}$, shear and axial forces $Q_{i}$ and $N_{i}$ and torques $K_{i}$, which according to (1) are obtained on the basis of the following equations:

$$
\frac{\partial U}{\partial M_{i}}=0 ; \quad \frac{\partial U}{\partial Q_{i}}=0 ; \quad \frac{\partial U}{\partial N_{i}}=0 ; \quad \frac{\partial U}{\partial K_{i}}=0 .
$$

The total number of unknown factors determines the degree of static uncertainty of the calculation schemes. The authors reduce the calculated models $8-12$ [1, 2, 4, 5] and even 24 times [3] statically indeterminate systems in relation to the internal force factors such as bending and torques moments, cutting forces.

Automation of the calculation in this case is possible only on the last stage of the system of linear equations solving (2) to find the internal force factors. The difficulty of automating the previous operations to obtain equations (2) is due to the peculiarities of structural structures, each of which requires special methods of approach.

Automation of calculations on MMPDE can be carried out if the uniform algorithm suitable for calculation of the SSS of various frame designs with use of a condition (1) is developed.

The aim of the work is to adapt energy methods to the automated calculation of SSS of frame structures by developing a single algorithm for finding internal force factors at the end of the process of finding the local minimum of the potential deformation energy $U$.

\section{Research results}

The development of an algorithm for automated calculation by energy methods should begin with simple structural structures in which the function of potential energy depends only on two force factors. This will not only simplify the task of compiling the algorithm, but will allow to visualize the processes of finding internal force factors using three-dimensional graphics software, such as Surfer, Matlab and others. [8].

One of the contours of the frame of the PEA-1A grab loader "Karpatets" was chosen for the calculation scheme (Fig. 1). Its contour consists of a longitudinal longeron 1. The lower reinforcing beam was introduced to increase the load-bearing capacity of the frame in the structure of the frame -2 . Additional reinforcement of the rigidity of the contour is carried out using a plate -3 (Fig. 1a), which rigidly connects the bearing elements 1 and 2 . Longeron and the lower reinforcing beam are made of standard channels № 20 (pos.1) and № 14 (pos. 2 Fig. 1b).

It is proposed to develop an algorithm for automated 

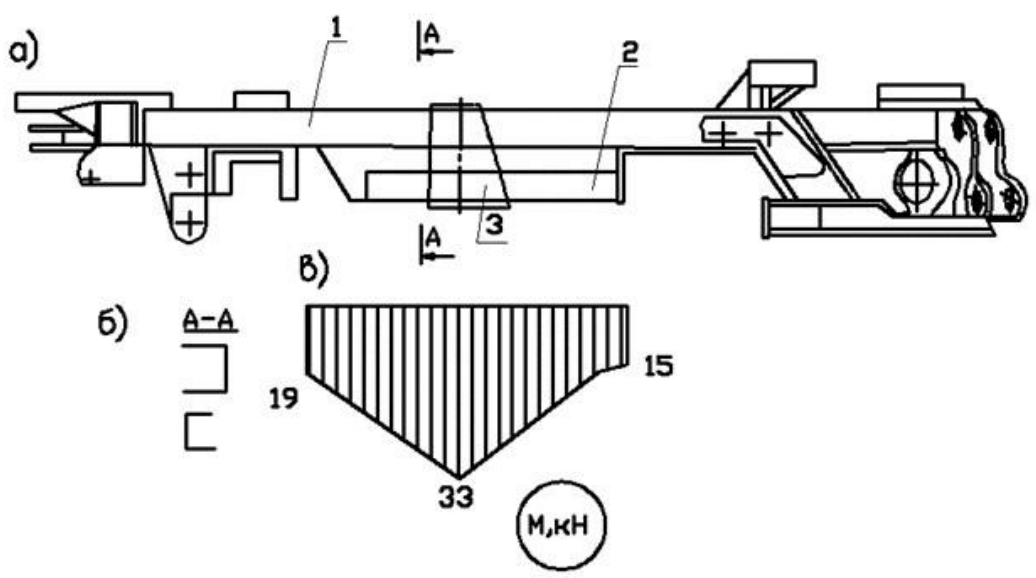

Fig. 1. Frame structure of the loader PEA-1A "Karpatets" a) loader frame, b) cross section,

c) bending moment diagram.
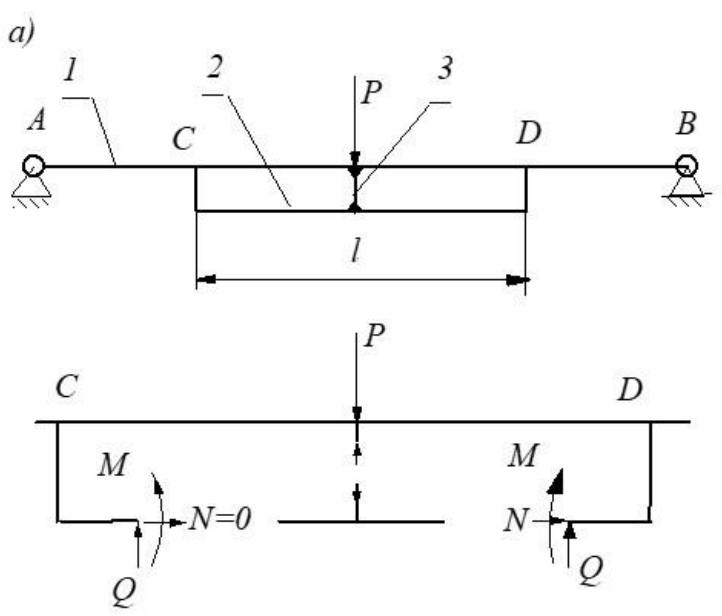

б)
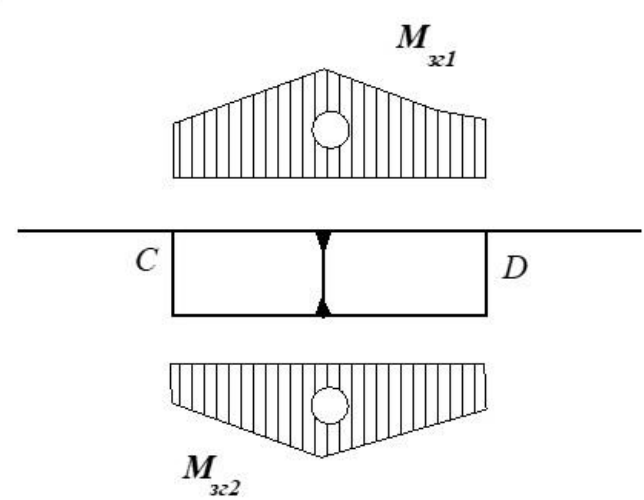

Fig. 2. Calculation model of the frame structure: $a$ ) - the action of internal force factors; $b$ ) - load diagram.

calculation of SSS of the given frame structure on the basis of MMPDE, which involves processing the function of potential deformation energy $U$. To do this, a calculation scheme (Fig. 2) with the accepted load in the form of a diagram of the bending moment $M_{32}$ is built (Fig. 1c). This load is distributed between the longitudinal longeron $M_{321}$ and the lower reinforcing beam $M_{322}$, which causes the appearance of internal force factors on the section $C D$ of the frame with length $l$ and with bending moment $M$ and the shear force $Q$ (Fig. 2).

In this case the potential energy of the frame section with load diagram shown in Fig. 2a, consists of the potential energies of the longeron $U_{I}$ and the lower beam $U_{I I}$ :

$$
\begin{gathered}
U=U_{I}+U_{I I}=\frac{1}{2 E J} \int_{0}^{l} M_{321}^{2} d x+\frac{1}{2 E J_{2}} \int_{0}^{l} M_{322}^{2} d x, \text { or } \\
U=\frac{1}{2 E J_{1}} \int_{0}^{l}\left\{M_{32}(x)-M_{322}[Q(x), M(x)]\right\}^{2} d x+\frac{1}{2 E J_{2}} \int_{0}^{l} M_{322}^{2}[Q(x), M(x)] d x
\end{gathered}
$$

That is, the function of potential energy (3) is reduced to the dependence of two variable force factors $Q$ and $M$, which allows to display function (3) in the form of a surface graph and visually check the efficiency of algorithms to find unknowns (Fig. 3a). It should be noted that with the transition to automated calculation methods, digital modeling of surfaces, as a rule, is carried out in the form of discrete values [9], which can be presented in the form of tables or matrices. From the function of potential energy (1) it is necessary to 

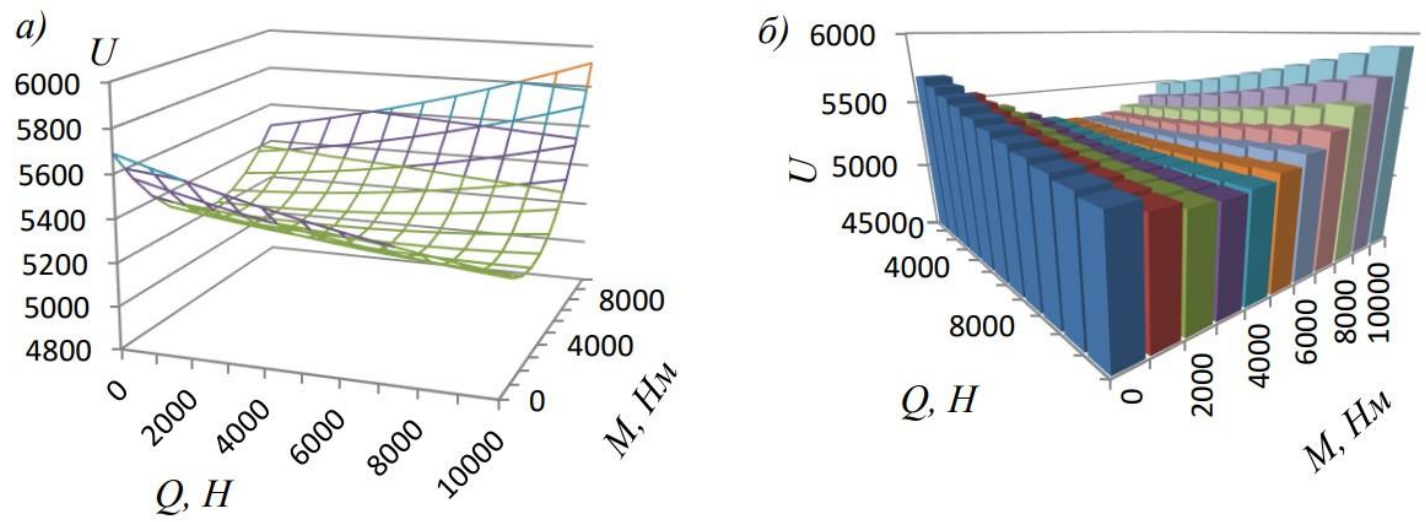

Fig. 3. Surfaces of the potential energy function $U(M, Q): a$ ) continuous surface according to formulas (3); $b)$ the surface in the form of discrete data.

continue with the discrete functional with a local point of a minimum (Fig. 3b). For convenience of processing, the array of discrete functional is reduced to dimensionless parameters using factor.

In the obtained functional the unknown $Q$ and $M$ act as variables, the variation of which requires achieving the condition:

$$
U(Q, M) \rightarrow \min
$$

In contrast to traditional methods, operations to obtain a system of equations (2) will be absent. Instead, the search for the local minimum $U_{\min }$ of function (3) is carried out according to the graph of the discrete surface (Fig. 3b) in the coordinate space of internal force factors. Their location is subject to condition (4) and is denoted as $Q=Q_{m}$ and $M=M_{m}$.

The set of discrete data can be applied to the methods of proof by exhaustion (grid), gradient descent and coordinate descent [10-12].

In the first stage, the method of proof by exhaustion (grid) was used to find the local minimum. Its essence was that within a given factor space:

$$
0 \leq Q \leq 20000 \mathrm{~N}, 0 \leq M \leq 10000 \mathrm{Nm},
$$

in the middle of which, as we believe, is the local minimum, a set of elements with values of potential energy in the form of a matrix (grid) is created. Its elements are located in the nodes of the grid through discrete steps $h_{Q}$ and $h_{M}$ relative to coordinates $Q$ and $M$.

A grid consisting of 1001 rows and 2001 columns was obtained for the specified factor space. The total size of the grid was 2003001 values. The resulting matrix is spatial, because within the factor space characterizes the distribution of the simulated feature in the form of a grid surface (Fig. 3b), the elements of which are characterized by a two-dimensional index, which clearly links their location in the matrix to the coordinate system of factor space.

Obtaining a matrix of grid-surface potential energy $U$ is considered the first step in the development of automated methods for calculating frame structures according to MMPDE.
The task of finding the minimum value of potential energy by the method of proof by exhaustion (grid) was to find in the array of the matrix of the element with the minimum value $U_{\min }$ and to determine its twodimensional index and accordingly establish the coordinates of internal force factors $Q_{m}$ and $M_{m}$.

According to the results obtained by the method of proof by exhaustion, the minimum element of the matrix with the value $U_{\min }=5206.26$, its location in the matrix the grid (21 row and 31 column) and the value of unknown force factors $Q_{m}=6920 \mathrm{~N}$ and $M_{m}=3810 \mathrm{Nm}$.

The method of proof by exhaustion is quite effective for automated calculation of frame structures with a small number of unknown force factors. As their number increases to $8-12$, the number of computational procedures increases sharply and, in this case, the method becomes ineffective in terms of organizing the dialogue when designing frames in CAD [12].

The next disadvantage of the complete search method is that the grid matrix is formed with constant discrete steps $h_{Q}$ and $h_{M}$ in the coordinates $Q$ and $M$. In this case, increasing the search accuracy is possible only with increasing the number of matrix elements within a given factor space, which again negatively impacts the time of problem solution [12].

The need for grid step variation follows from the properties of the grid surface. The obtained grid of values shows the grid surface of the potential energy in the form of horizontals - isolines with the same values of $U$ (Fig. 4a). Figures 3 and $4 a$ show that the surface has the shape of a "channel" with a decrease in steepness when approaching the minimum point. This means that in the region of the minimum value of the simulated feature in order to localize the extremum, it is necessary to reduce the step of the discrete grid. Thus, when the feature deviates from the minimum value of $U_{\min }$ to $U=5208$ (Fig. 4b), the force $Q$ can take values that are limited by the contour $I$, in the range of $5500 \ldots 8400 \mathrm{~N}$, and, accordingly, the bending moment $M=3600 \ldots 4300 \mathrm{Nm}$. When the feature increases to $U=5210$, the limits become even larger (contour II) $Q=4000 \ldots 10000 \mathrm{~N}$, and $M=3200 \ldots 4700 \mathrm{Nm}$ (Fig. $4 \mathrm{~b}$ ).

This example illustrates that the step of the discrete 

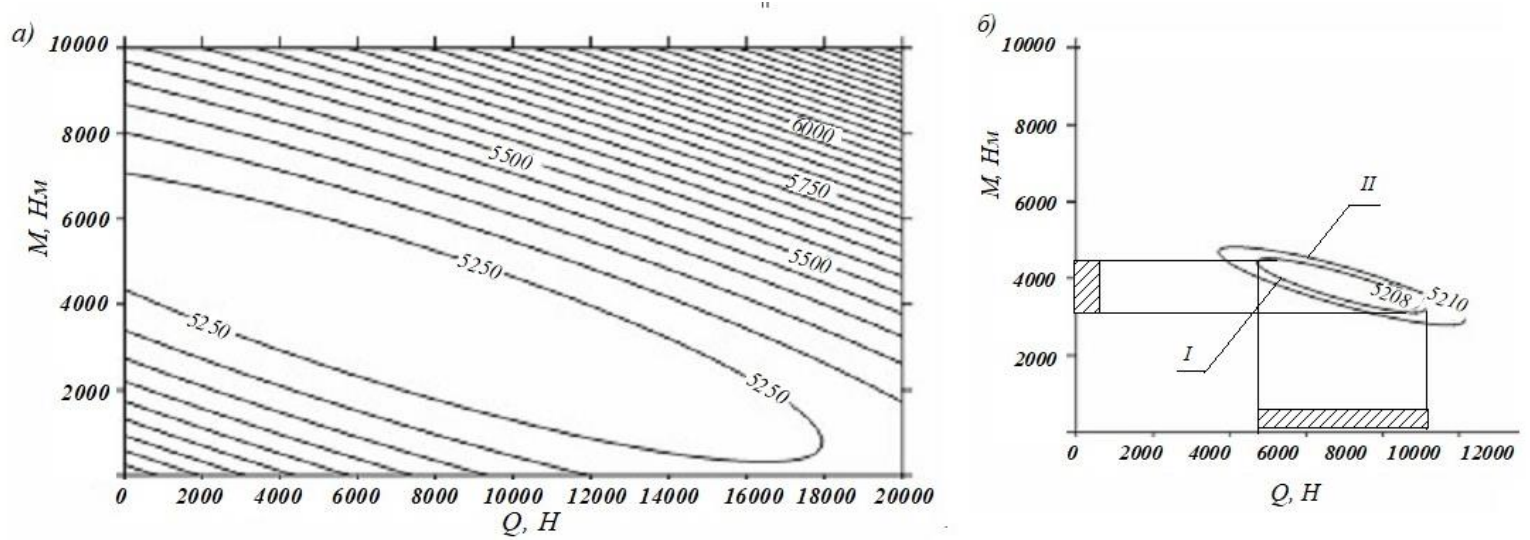

Fig. 4. Isolines of the surface of the potential energy function $U(Q, M)$.

a) surface isolines with an interval of $50 ; b$ ) the contour of the minimum limited by isolines 5208 and 5210 .

grid must be reduced when approaching the minimum point, which will reduce the number of calculations when determining the unknown $Q$ and $M$.

In the method of proof by exhaustion, it is impossible to perform operations with decreasing grid step, because the available logical comparison procedures used to find the minimum element do not take into account the gradient of decreasing the value of the function.

An attempt to use functions (2) as a condition for finding the minimum value of $U_{\min }$, leads to a gradient descent method. By means of Surfer [8] the grid surface of the gradient of the function $U$ with coordinates $Q=\frac{\partial U}{\partial Q} \quad$ and $\quad M=\frac{\partial U}{\partial M} \quad$ was obtained. However, due to the discrete representation of the data to the gradient $U$, exact conversion to zero becomes impossible. It approaches zero with an accuracy of $\varepsilon=$ $1 \cdot 10^{-5} \div 1 \cdot 10^{-4}$. Therefore, the problem is replaced by finding the minimum value of $U_{\text {min }}$, which is described by the previous algorithm. In addition, obtaining an additional gradient grid surface further complicates the calculation process.

Therefore, it is advisable to develop a new method of automated calculation of SSS of frame structures, which is based on the solution of the following principles. This is the ability to perform logical operations to compare the values of adjacent cells and change the discrete step when approaching the point of the local minimum, when the search process goes to a flat surface.

The implementation of these principles is carried out in the method of coordinate descent, which is quite effective in cases of a single minimum function [11]. In the method of coordinate descent, as well as in the method of proof by exhaustion, only the numerical values of the function (3) are used in the form of discrete data. The peculiarity of the method is that it does not require the construction of a grid surface for the entire factor space, which significantly reduces the number of computational operations. The numerical values of the function (3) itself are written in a small window of the sliding matrix.

The search for the minimum of the function $U$ for two factors $Q$ and $M$ is carried out by sliding a matrix window with size of $3 \times 3$ cells on the grid surface. The values of the cells in the window are filled with the step $h_{Q}$ and $h_{M}$ on the fluid coordinates $Q$ and $M$ of the grid surface.

The algorithm for finding the minimum of the function is as follows. The matrix window is placed on the grid surface so that the starting point $C_{0}$ is in the center of the matrix - the element $a_{22}$. Other values of the matrix are calculated by formulas (3) with steps $h_{Q}$ and $h_{M}$ in the vicinity of the grid size $3 \times 3$. On the basis of the formed array $3 \times 3$ the minimum element is defined

$a_{\min }=\min \left(a_{11}, a_{12} \ldots a_{33}\right)$,except for the element $a_{22}$.

The matrix window is moved along the grid surface so that the found minimum element is in the center of the matrix window. It is assigned an index and it takes a new minimum value of $a_{22}=a_{\text {min }}$. Other elements are calculated similarly by formulas (3) with the same steps $h_{Q}$ and $h_{M}$.

Moving the window matrix of size $3 \times 3$ is possible in eight directions, which are denoted as $p, q, r, s, t, u, v$, $w$ (Fig. 5). The directions of movement can be oriented relative to the coordinate axis $M$ by the directional angle.

The multiplicity of the directional angle is $\frac{\pi}{4}$ and it can take values:

$$
\frac{\pi}{4} n, \text { where } n=0 \ldots 7
$$

The development of the method of coordinate descent is that the movement from the initial point $C_{0}$ to the next was carried out strictly in the vertical or horizontal directions, i.e. when one of the coordinates is fixed [11]. In the proposed method, additional movements at an angle multiple of $\frac{\pi}{4}$ are possible (6).

In addition, a new algorithm for changing the movement step is proposed. As already mentioned, the movement of the sliding matrix is the size of the grid, which acts as a step of the coordinate descent. The 


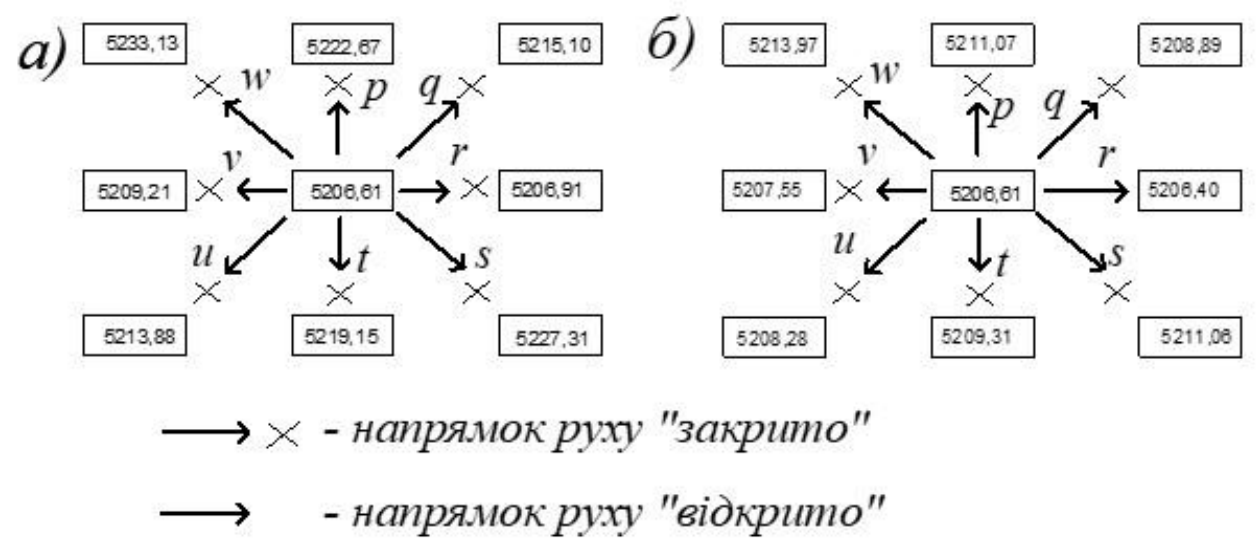

Fig. 5. Directions of movement of the sliding matrix-window on the grid-surface. a) the situation of "dead end"; $b$ ) the possibility of exit from the "dead end".

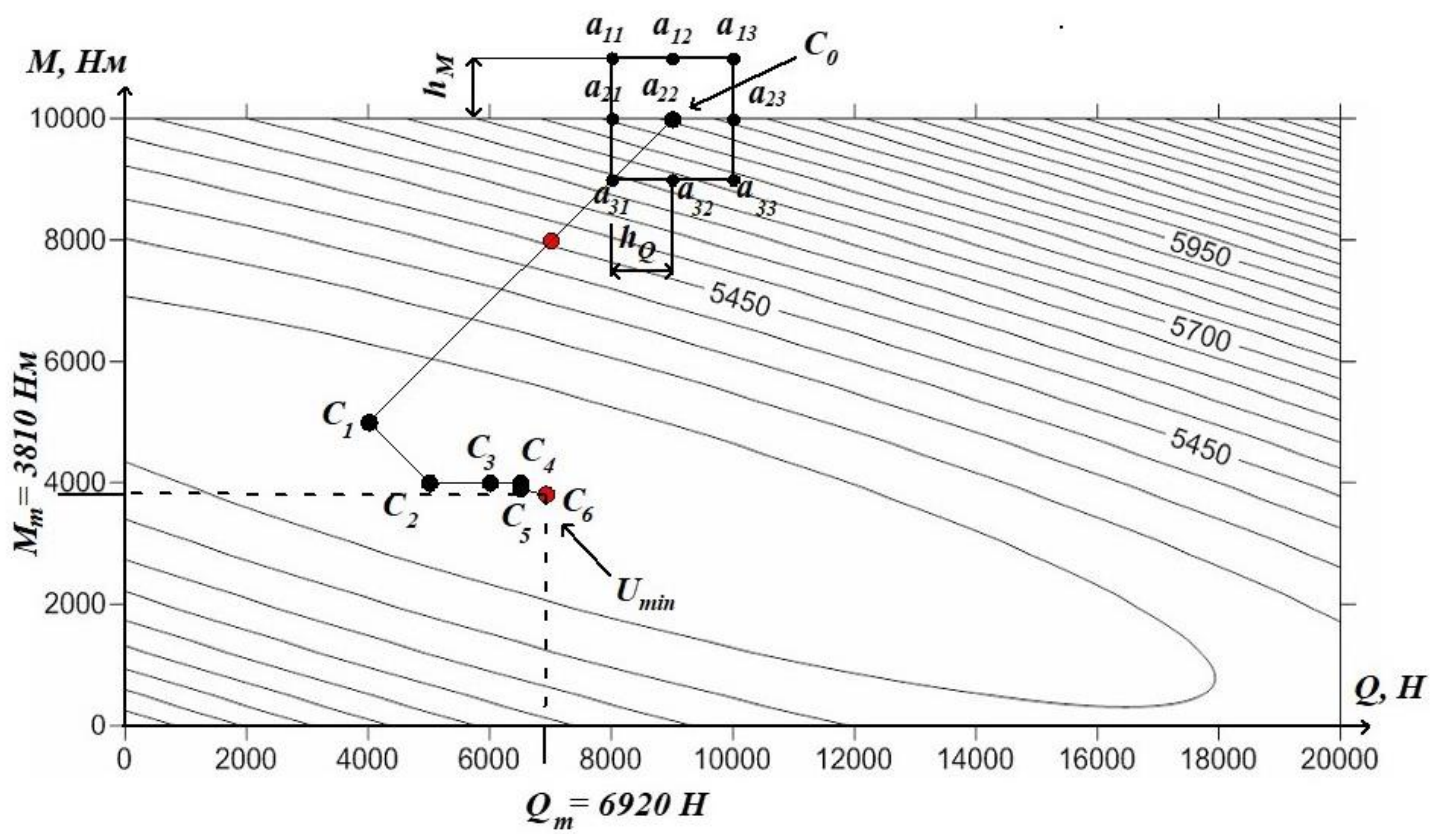

Fig. 6. Operation of the algorithm for finding the minimum value of the potential deformation function $U_{\text {min }}$ by the method of coordinate descent.

movement occurs towards the smaller element that corresponds to condition (5).

An interesting case is the situation when the central element of the matrix $a_{22}$ will be the smallest element that violates the transition condition (5). It also means that all possible eight directions of movement of the matrix are closed (Fig. 5a). In this case, the descent operation is "dead end", as evidenced by the fact that the matrix has approached the local minimum at distances of $Q_{m} \pm h_{Q}$ and $M_{m} \pm h_{M}$. Exit from the "dead end" and further movement of the matrix-window becomes possible if you reduce the values of the discrete steps $h_{Q}$ and $h_{M}$ in the descent operations. The steps $h_{Q}$ and $h_{M}$ can be reduced, for example, by twice, then for all the extreme elements of the matrix the values will be recalculated for a new step (Fig. 5b). The recalculation of the elements returns condition (5) to execution, and the matrix begins to move in the direction of the minimum element $a_{23}$, but with a reduced step.

The operation of the coordinate descent algorithm is illustrated in Fig. 6. The random point $C_{0}$ with initial values $Q=10000 \mathrm{~N}$ and $M=9000 \mathrm{Nm}$ is chosen on the graph. The problem of the algorithm was to reach from the starting point $C_{0}$ by the method of coordinate descent such a point to which condition (4) is fulfilled and to determine the values of $C_{m}$ and $M_{m}$.

At the first stage of the descent operation, the values of discrete steps $h_{Q}=1000 \mathrm{~N}$ and $h_{M}=1000 \mathrm{Nm}$ along the $Q$ and $M$ axes were set. The descent process was started from the starting point $C_{0}$ and in seven steps the point $C_{2}$ was reached with values $Q=6000 \mathrm{~N}$ and $M=$ $4000 \mathrm{Nm}$. At point $C_{2}$ there was a situation of "dead end" and the descent process stopped (Fig. 5a). Exit from the "dead end" was carried out by reducing the step to $h_{Q}=$ $500 \mathrm{~N}$ and $h_{M}=500 \mathrm{Nm}$, which allowed (Fig. 5b) to continue the descent process and go to point $C_{3}$ with 
values of $Q=6500 \mathrm{~N}$ and $M=4000 \mathrm{Nm}$. From point $C_{3}$, similarly, three more steps were performed at $h_{Q}=100 \mathrm{~N}$ and $h_{M}=100 \mathrm{Nm}$ with the transition to point $C_{4}(Q=$ $6700 \mathrm{~N}$ and $M=3900 \mathrm{Nm}$ ), and then with steps $h_{Q}=50$ $\mathrm{N}$ and $h_{M}=50 \mathrm{Nm}$ to point $C_{5}$, where the operation was again at a dead end. The values obtained at point $C_{5}(Q=$ $6800 \mathrm{~N}$ and $M=3850 \mathrm{Nm}$ ) indicated that the point of the local minimum is at a distance along the axes $Q_{m} \pm 50 \mathrm{~N}$ and $M_{m} \pm 50 \mathrm{Nm}$. Therefore, at point $C_{5}$, the step was again reduced to $h_{Q}=10 \mathrm{~N}$ and $h_{M}=10 \mathrm{Nm}$. Then in eleven steps the local minimum of the potential function $U=U_{\min }=5206.2577$ is reached, which corresponds to the value of $Q=Q_{m}=6920 \mathrm{~N}$ and $M=M_{m}=3810 \mathrm{Nm}$ up to the value of the last step. Actually, such values of $Q_{m}$ and $M_{m}$ were obtained by the method of proof by exhaustion (grids). In this step, the descent operation was stopped to compare the effectiveness of the described two methods with the same results.

In the method of proof by exhaustion (by the method of grids), in order to fill all nodes of the grid, it was necessary to perform 2003001 calculations. In the method of coordinate descent, the point of local minimum was reached in 27 steps. At each step, the values of a window matrix of size $3 \times 3$, i.e. nine elements, were calculated, and the final result was obtained in just 243 calculations.

Thus, the method of coordinate descent for two factors significantly reduces the number of calculations and is effective enough to search for unknown force factors according to condition (4) according to MMPDE. The method of coordinate descent has great tactical flexibility, because if there is a situation of "dead end", it returns to the most successful attempt and changes the step and direction of the search. Therefore, the method is sufficiently adapted to find the global optimum.

In addition, this method does not require finding partial derivatives in analytical form, because differentiation increases the complexity of the problem and the probability of errors in its implementation.

The described algorithm for a three-dimensional surface, which considers only two factors, can be extended to n-dimensional space with many unknowns.

Especially valuable is that the proposed algorithm can be used for automated calculation of real statically indeterminate frames with 8 - 12 unknown internal force factors. In contrast to the method of proof by exhaustion, which would require the construction of a grid for an ndimensional cube, which is associated with a large number of calculations, the proposed method of coordinate descent will significantly reduce the calculations

The stability of the method of coordinate descent from finding unknown internal force factors of the frame structure is proved on the model of two factor variables. The coordinate descent algorithm is implemented in the programming language Visual Basic Application (VBA) [13] in Excel.

\section{Conclusions}

The paper shows that the adaptation of energy methods for automated calculation of frame constructions of agricultural vehicle bases on the development of a sole algorithm applicable to different construction schemes. The calculation outset still remains the idea of getting a function of potential energy of deformation as a function with unknown inner power factors. Search for local function minimum of potential power of deformation has been based on its discrete gridsurface, which allowed us to change operations from partial derivative search to automated search for local minimum. This operation has been obtained by modified coordinate descent method applying skid matrix on the grid-surface.

The paper describes the algorithm for frame construction with two unknown power factors and shows that the method is adapted to global optimum search. We also managed to reach the tactical flexibility of coordinate descent method in attempts to continue approaching to local minimum in cases of a dead end situation by changing the discrete course.

It has been offered to extend the implemented algorithm from 3-D surface, which deals only with two power factors, to n-D one with many unknown values. This algorithm can be a basis of automated methods for calculation of real statically undefined frames with $8-12$ unknown inner power factors.

Ripetskyy E. - Doctor of Technical Sciences, Associate Professor, Professor of Geodesy and Land Management; Ripetskyy R. - Ph.D., Associate Professor, Associate Professor of Higher Mathematics;

Pidgurskyi M. - Professor, Doctor of Technical Sciences, Professor of the Department of Engineering of Mechanical Engineering Technologies;

Pidgurskyi I. - Senior Lecturer of the Department of Structural Mechanics

Korobkov O. - postgraduate.

[1] T.I. Rybak, Search design on the basis of resource optimization of mobile agricultural machines (Zbruch, Ternopil, 2003).

[2] M.I. Pidhurskyi, Methods for forecasting the life of bearing and functional systems of beet harvesters (TNTU im. I.Puliuia, Ternopil, 2007).

[3] P. Popovych, M. Stashkiv, T. Dovbush, Scientific Journal of the Ternopol National Technical University 78(2), 153 (2015) (DOI: 10.33108/visnyk_tntu).

[4] T. Rybak, Ye. Ripetskyi, S. Sikorskyi, Scientific Journal of the Ternopol National Technical University 66(2), 97 (2012) (DOI: 10.33108/visnyk_tntu).

[5] T.I. Rybak, M.Ia. Stashkiv, Ye.I. Ripetskyi, Journal of Kharkiv Petro Vasylenko National Technical University of Agriculture 69, 85 (2008). 
[6] S.Iu. Eremenko, Eremenko, Finite element Method in the Mechanics of a deformed Body (Osnova, Kharkov, 1991).

[7] Ye.I. Ripetskyi, R.I. Ripetskyi, V.M. Senychak, Journal of Kharkiv Petro Vasylenko National Technical University of Agriculture 170, 142 (2016).

[8] Surfer. User's Guide. Contouring and 3D Surface Mapping for Scientists and Engineers (Golden Software, Inc.Golden, Colorado 2002).

[9] Ye. Ripetskyi, T. Rybak, O. Ivanchuk, Scientific Journal of the Ternopol National Technical University 70(2), 114 (2013) (DOI: 10.33108/visnyk_tntu).

[10] A.E. Mudrov, Numerical methods for PC in BASIC, FORTRAN and Pascal (Rasko, Tomsk, 1991).

[11] Yu. Nesterov, Efficiency of coordinate descent methods for huge-scale optimization problems (CORE Discussion Paper 2010/2, 2010).

[12] M.A. Volk, T.V. Filimonchuk, R.N. Gredel, Scientific Works of Kharkiv National Air Force University 1(19), 100 (2009).

[13] R.W. Larsen, Engineering with Excel (Pearson Publishing, 2017).

\section{Є. Ріпецький ${ }^{1}$, Р. Ріпецький ${ }^{1}$, М. Підгурський ${ }^{2}$, І. Підгурський ${ }^{2}$, О. Коробков ${ }^{1}$}

\section{Адаптація енергетичних методів до автоматизованих розрахунків рамних конструкцій мобільних машин}

\footnotetext{
${ }^{1}$ Івано-Франківський національний технічний університет нафти і газу, Івано-Франківськ, Украйна, егір@і.иа ${ }^{2}$ Тернопільський національний технічний університет імені Івана Пулюя, Тернопіль, Украӥна, pidhurskyу@gmail.com
}

Показано, що адаптація енергетичних методів до автоматизованого розрахунку рамних конструкцій мобільних машин полягає в розробці єдиного алгоритму придатного до різних конструктивних схем. Відправним пунктом розрахунку залишається отримання виразу потенціальної енергії деформації у вигляді функції з невідомими внутрішніми силовими факторами. Пошук локального мінімуму функції потенціальної енергії деформації здійснено на основі іiі дискретної grid-поверхні. Досягнуто тактичну гнучкість методу покоординатного спуску при спробах продовжити наближення до локального мінімуму у випадках виникнення ситуації «тупику» шляхом зміни дискретного ходу. Запропоновано поширити реалізований алгоритм від тривимірної поверхні, який розглядає два силових фактори, до n-мірного простору з багатьма невідомими.

Ключові слова: енергетичні методи, рамна конструкція, потенціальна енергія деформації, внутрішні силові фактори, grid-поверхня, метод покоординатного спуску. 